Violência 



\section{Os medos na política de segurança pública ${ }^{1}$}

\section{$A L B A Z A L U A R^{I}$}

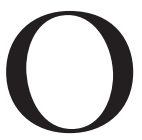

MEDO TEM sido tratado comumente como o que decorre das notícias veiculadas na mídia sobre crimes; no pensamento social, há o medo como resultante do terror do Estado que oprime os cidadãos. Este ensaio almeja demonstrar que há muitos outros problemas relacionados com o medo que afetam a construção e a eficácia das políticas públicas de segurança em grande medida porque tendem a negar a presença do medo na subjetividade dos agentes e da população afetada por elas. Uma perspectiva diferente que, sem negar a importância da formação do Estado, focaliza as experiências de vida e as emoções desencontradas das pessoas envolvidas em situações perigosas que as fazem temer por suas próprias vidas, riscos cada vez mais comuns no Brasil. O medo que se deve temer é o medo de ser morto ou torturado pelas armas das organizações estatais ou ilegais.

O ensaio parte da ideia de que negar o medo é deixar a pessoa entregue a emoções que ela não controla. Negar o medo é aceitar que continue limitando a liberdade de ação dos indivíduos paralisados pela sensação de que algo cruel e penoso os ameaça. Na doutrina liberal, o medo é algo a combater para liberar a ação individual tolhida, no que uma autora denominou o liberalismo do medo, doutrina política que pensa em como evitar que o indivíduo seja vítima da crueldade, ou seja, a imposição deliberada de dor física ou moral pelo mais forte sobre o fraco (Shklar, 1998). Para essa crueldade do mais forte, os moradores do Rio de Janeiro têm um nome: covardia. Por isso, o monopólio da violência ou dos instrumentos da coerção pelo Estado é considerado uma ameaça perene à liberdade dos cidadãos que devem se curvar à repressão do Estado para escapar à punição ou ao abuso no uso da força pelos seus agentes. A saída liberal aponta em várias direções, a mais usada sendo a de garantir que nenhum desses servidores do Estado possa intimidar alguém, a não ser pelo uso de procedimentos legais bem compreendidos e aceitos (Shklar, 1998, p.13). Na saída liberal também devem ser contidos os que, não agindo em nome do Estado, intimidam ou matam pessoas em nome dos seus interesses individuais ou fins ideológicos coletivos. Desafios e situações complexas impedem uma solução única e clama por pensá-las para além do Estado. Mais do que conceituar, é preciso entender os mecanismos micro e macrossociais dos abusos de poder.

Embora tenhamos coordenado e participado de pesquisas de vitimização cujos resultados já foram publicados, as reflexões aqui expostas não advêm ape- 
nas dos dados acerca da sensação de segurança. Dessas pesquisas ficou claro que a sensação de segurança, similar à ausência de medo, se correlaciona mais fortemente com a variável "ouvir tiros", 2 que tem percentuais muito altos em algumas áreas do Rio de Janeiro, do que com a existências de terrenos baldios ou carros abandonados, que têm percentuais baixos na cidade, especialmente nas favelas onde os tiros são ouvidos sempre ou frequentemente por conta da guerra entre as facções, e delas com a polícia. Mais do que a infraestrutura urbana, é a presença de hospitais no bairro e de policiamento na vizinhança, além de serviços públicos como a iluminação das ruas que trazem maior sensação de segurança (Zaluar et al., 2006). Assim, se, por um lado, no pensamento político, é o Estado que provocaria o medo para afirmar o seu domínio (Shklar, 1998), por outro, a população precisa e quer a proteção do Estado para superar o medo. As disposições e posturas individuais, ou seja, as subjetividades, devem ser incluídas na análise.

$\mathrm{Na}$ perspectiva microssocial e intersubjetiva aqui adotada, não há um só medo a ser considerado na construção da política de segurança pública, necessariamente vinculada à saúde. Há vários medos: o dos combatentes; o dos civis afetados diretamente pelos confrontos armados entre os combatentes; o dos moradores das cidades difusamente afetados por sensações advindas dos confrontos entre grupos distintos e da criminalidade urbana comum, isto é, furtos, assaltos, agressões, latrocínios, assassinatos interpessoais. Esses medos diversos não são apenas emoções instintivas que se expressam fisicamente na fisionomia, na tensão muscular, no suor frio e outras manifestações corporais do medo, mas são produzidos ou construídos pelos significados socialmente remetidos às emoções e aos objetos considerados como a fonte do medo. Mas apenas na experiência direta do ataque violento ou da ameaça de morte, os sintomas físicos se fazem visíveis e pode-se falar de algo próximo a uma emoção básica do medo (suores, taquicardia), embora mesmo nessa situação extrema de perigo à vida da pessoa haja lugar para a definição do que é a ameaça, quem ou o que ameaça, e a construção da resposta a ela. Nas demais experiências, é a construção social do medo, da situação de ameaça, do objeto ameaçador que predomina sobre a emoção básica, quase impossível de ser percebida. Em qualquer caso, não há uma resposta inata ao medo que anda sempre misturado a outras emoções desde a raiva, passando pela desconfiança e a insegurança -, cujas reações podem variar da paralisia até a fuga célere da situação (Stearns; Stearns, 1986).

Primeiramente, o medo dos servidores do Estado ou combatentes, aqueles que agem para provocar o medo nos que supostamente desobedecem às leis do país ou ameaçam a "ordem” pública. Numa política de segurança que valoriza o combate armado, é preciso lembrar que os agentes também sentem medo, também reagem às situações de batalha em que são envolvidos. Portanto, é preciso entender o que tolhe ou direciona a ação deles, o que é pouco pensado nas políticas de segurança, a não ser recentemente para incluir os efeitos da 
síndrome do estresse pós-traumático como um dos problemas na execução dessa política. Esse medo é um dos pontos de interseção entre a política pública da saúde e da segurança pública. Mas deveríamos pensar primeiro sobre as características dos confrontos armados que acontecem em várias cidades brasileiras para discutirmos melhor as propostas sobre a mesa de discussões, além de sublinhar a necessidade de colaboração entre essas políticas.

Que guerras estão em curso nelas? Recentes estudos internacionais falam de guerra irregular, intermitente, selvagem e sem limites institucionais que teria se espalhado pelo mundo no que se denominou Transnational Organized Crime (TOC), cuja principal característica é o alto grau de complexidade organizacional e de profissionalização, adicionado à notável dispersão espacial com outros grupos e atividades-meio - como o tráfico de drogas - para consecução de seus objetivos (Sain; Games, 2014, p.121). O que tem chamado a atenção dos estudiosos dessas guerras é que são encontradas tanto entre os empreendimentos baseados em negócios ilegais que trazem muito ganho ao garantir a impunidade de seus agentes quanto nas organizações religiosas ou etno-políticas fundamentalistas, justificadas pela verdade incontestável das suas crenças. O que há de comum nessas organizações com características tão diferentes é o uso de armas leves, porém muito letais - que podem ser colocadas nas mãos de pessoas muito jovens, até mesmo crianças -, assim como a facilidade com que ultrapassam as fronteiras porosas entre países com institucionalidade fraca ou falha $(\mathrm{OECD}$, 2012). Fazem parte do processo de globalização, aquele que já foi chamado de globalização das trevas ou infraglobalização por ser pouco visível, mas destruidor da governança, do respeito às leis e aos direitos, ou seja, ao Estado democrático de direito. Segundo Banfield (2014, p.20),

O uso da força, ameaças, o controle de monopólio e/ ou a corrupção de funcionários públicos são táticas-chave no modus operandi de COT. As drogas representam a mais importante e lucrativa mercadoria ilícita, alguns estimando que somariam $85 \%$ do valor total global das transações do COT. Estados frágeis são importantes pontos de trânsito e cumprem funções intermediárias nos elos globais de COT, pois oferecem "fronteiras porosas, funcionários mal pagos e indiferença ou consentimento público".

Essa guerra difere, portanto, das guerras convencionais dos séculos passados quando o confronto se dava com alguma proximidade entre os combatentes por conta do instrumento - baionetas e demais objetos cortantes - ou do pouco alcance das armas de fogo então disponíveis. A linha divisória se deu nas guerras mundiais do século XX, quando a destruição passou a ser feita a maior distância e com armas muito mais letais, que já incluíam armas de longo alcance. Por isso, segundo estudiosos do tema, a descarga de adrenalina ou a tensão nervosa não seria aliviada pela satisfação no contato que resultaria na morte visível porque próxima do inimigo ameaçador. Essa morte, tão junta do próprio corpo, teria um efeito orgástico pela ação de matar com a baioneta e sentir/ver o sangue do 
inimigo correr (Bourke, 2006, p.201). Na falta desse alívio imediato da tensão e do resultado dessa mortandade impressionante, que passou a atingir tanto combatentes quanto civis, foi a facilidade com que o pânico, um medo agravado pelo descontrole das demais emoções, se espalhou. $\mathrm{O}$ anonimato entre os inimigos e a agressão aleatória, cujo ponto de origem é desconhecido, pois não se sabe de onde veio o tiro nem quem ele atingiu nos quilômetros de seu alcance, prejudicou até mesmo a disciplina necessária entre os combatentes, bem como entre os civis responsáveis pela proteção dos não combatentes. Na Inglaterra, por exemplo, senhoras responsáveis pelos abrigos dentro das estações de metrô começaram a culpar imigrantes, judeus, estrangeiros, pessoas de pele mais escura pelas desordens que surgiam, quebrando a solidariedade necessária nessa ação de defesa da vida (Meerloo, 1946, p.94-5). Essa explosão de emoções teve continuidade até depois da assinatura do Tratado de Paz quando as nações europeias começaram a ser reconstruídas ainda envoltas no medo, na ansiedade e no ressentimento, emoções relacionais vividas coletivamente (Biess, 2010, p.37-42).

Sobre os combatentes dessa guerra, vários estudos apontam para a ínfima proporção dos que não sentiam medo (apenas 7\%), bem como para o fato de que o montante de medo poderia até ameaçar a missão militar por corroer a disciplina e enfraquecer a lealdade aos demais companheiros de luta. O medo, nesses casos, criaria danos subjetivos ainda mais graves que os físicos na medida em que abalava o cerne da disposição para a luta, a disposição guerreira.

Um desses estudos aborda questão que pode ser a base para entendermos porque policiais brasileiros matam tanto e são assassinados tão frequentemente. Pois, segundo o autor, os soldados afirmaram que, sob o domínio do medo, podiam disparar suas armas de maneira descontrolada ou serem incapazes de se proteger, de substituir a munição e de proteger o companheiro (Hall, 1920, apud Bourke, 2006, p.199-200). A covardia tornou-se ainda mais presente nessa guerra tão indeterminada.

Assim deparamos com a outra face do etos guerreiro reforçado na política de segurança de combate armado ao tráfico: é a que anula a construção moral do homem corajoso e infalível no desejo de destruir o inimigo, o etos guerreiro (Elias, 2000; Zaluar, 2004), ao pensar primeiro em salvar a própria pele. As duas faces dessas disposições presentes na guerra deveriam ser trabalhadas na formação do policial, bem como na prevenção da violência entre os jovens vulneráveis, pois uma delas é uma construção imaginária de força e determinação que os ilude; outra é a realidade da experiência concreta de enfrentamento da morte que os faz tão facilmente matáveis e covardes por causa do medo.

No contexto dos conflitos armados em países que não estão envolvidos em nenhuma guerra declarada, como o Brasil, estudiosos têm proposto um outro nome para designá-los: "conflitos civis” (Beal; Goodfellow; Rodgers, 2013), sublinhando apenas os problemas advindos da urbanização e dos contextos urbanos, sem referência ao crime organizado. Embora esses conflitos tenham como 
protagonistas cidadãos comuns, outras pesquisas afirmam que, no Rio de Janeiro, os jovens desenvolvem o etos guerreiro nas experiências de combate nas quais aprendem a lutar e a ser implacáveis com o inimigo, atributos masculinos de força valorizados na guerra em que diferentes facções de traficantes se engajam (Zaluar, 1994; 2004). Por isso, considera-se que o conceito de guerra irregular é mais apropriado para indicar essas guerras contínuas ou mesmo "sem fim", baseadas na disputa de pontos de venda de drogas ilegais e de vingança pessoal.

A incorporação acrítica dos estilos de juventude que aclamam a violência avançou no processo de globalização cultural, bem como a adoção de uma política extremamente repressiva sobre alguns dos seus efeitos, em especial o uso de drogas ilegais. Sem o estudo desses aspectos cruciais da questão social, será impossível montar políticas públicas eficientes para a construção de uma sociedade mais justa e pacífica. Como já se afirmou anteriormente, no Brasil, não se trata, como em África, Ásia e Europa do Leste, onde exércitos mobilizam crianças e adolescentes, de trazer a criança de volta à escola, à família, à vizinhança, deixando de ser soldados. Trata-se de melhorar a escola pública de modo que não se tornem defasados no estudo e acabem desistindo dela. Trata-se, portanto, de diminuir o contingente de jovens pobres que não trabalham nem estudam, que vagam pelas ruas, que reforçam as hostes dos que procuram as quadrilhas para se sentirem protegidos e encontrarem fontes de poder, dinheiro e aceitação de seus pares. São esses jovens os identificados como bandidos e enfrentados em batalhas. Para isso, é preciso que tais jovens compreendam também a fragilidade dessa proteção e admitam o medo facilmente transformado em pânico que os faz tão mais suscetíveis à morte, mas sobretudo diminuir o contingente de armas disponíveis para as guerras privadas que desenvolvem entre si e as guerras públicas dos policiais contra eles.

Logo, devemos perguntar, as guerras irregulares envolvendo também forças estatais são necessárias? Como quase todos agora repetem, a investigação deveria substituir a repressão ou o uso da força bruta. A guerra às drogas é hoje considerada por muitos uma política falida que deve ser substituída por outras políticas que tratem a questão do uso de drogas como questão de saúde pública em que a prevenção e o tratamento são cruciais para diminuir o abuso e a violência associada ao tráfico. Confrontos armados deveriam ser a última escolha porque nada garante que a paz que resultará deles não será apenas imposta, mas incompreendida e inaceitável pela população local. É preciso pensar sobre como e que paz construir, eliminando a possibilidade de ser uma paz romana que simplesmente acaba com os confrontos armados e impõe uma ordem não legitimada. A paz se constrói na política, na negociação cotidiana para se tornar uma disposição internalizada, no diálogo e no convencimento, ou seja, no etos civilizado.

Os dilemas que sempre acompanham operações envolvendo as forças militares já estão postos há tempos, muito longe das soluções liberais. Por 40 anos, 
gestores públicos, legisladores e os próprios “cidadãos de bem”, assim autodenominados, apostaram em modelo de segurança pública já superado porque atua reativamente e não proativamente, dentro da lógica da guerra às drogas ou ao crime. Na América Latina essa política ficou conhecida como "mano dura": para combater o crime, mais repressão, mais penas, mais prisões, ou seja, superpopulação carcerária, prisões provisórias, ineficácia na investigação, ineficiência na dissuasão, incapacidade na prevenção, ou seja, a política de "enxugar gelo". $\mathrm{Na}$ concepção da repressão, somente a polícia, o sistema judiciário e a administração penitenciária seriam responsáveis no combate aos crimes cometidos, usando muito mais os métodos da força repressiva do que o da investigação que seria mais eficaz para desmontar as organizações que fazem do crime um negócio constante. Além da investigação que pode prender sem o confronto armado que mata, a segurança pública envolve também a dissuasão e a prevenção que afeta a vontade de praticar crimes antes que eles sejam cometidos, daí a sua comprovada eficácia a custos menores e sem efeitos colaterais danosos, como a perda de vidas e a destruição de patrimônios privados e públicos.

Mesmo que a intervenção seja iniciada com a justificativa de prender traficantes ou assaltantes, apreender armas e drogas nas áreas onde estão concentradas, é impossível negar que nem a guerra se ganha apenas com a espada, cuja força, numa democracia, tem de ser controlada. Portanto, se a intervenção policial e militar optar por sublinhar o caráter repressivo de combate ao crime e aos criminosos nas áreas violentas da cidade, não poderá deixar de negociar seus passos com os mais afetados pelas operações de contenção ao crime. Se for pensada como missão de paz, deve ser entendida como política de aproximação com a população local, inclusive de negociação e diálogo com as organizações e coletivos locais. Esse é o princípio das novas formas de policiamento e, mais ainda, das missões de paz internacionais. Tudo isso aponta para a necessidade de deixar o improviso para pensar num plano que coordene as ações dos atores envolvidos e que possa ser compreendido e consentido pelos moradores da cidade.

Hoje, os estudos estratégicos, de raiz militar, foram sendo substituídos por estudos de segurança pública entendidos de forma mais abrangente. Em qualquer missão de paz, preconiza-se dimensionar o alcance da ideia de paz para valores e políticas em curso, assim como o seu lugar no debate cognitivo e a importância que a não violência tem nos processos de transformação política. Há que participar ativamente desse debate nas escolas, na mídia, no espaço público de discussão. Como aumentar a capacidade de cooperação e de negociação de conflitos na cidade? Que paz querem as Forças Armadas e as polícias? Será meramente o controle das armas que aqui chegam, sem dúvida nenhuma eficaz para diminuir os homicídios? Ou será uma mudança cultural mais profunda que busca desenvolver disposições não violentas, não guerreiras, para a vida numa democracia constitucional em que a cooperação, a mediação e a negociação de conflitos são pilares imprescindíveis? A dimensão política mais uma vez fica 
evidente e a força moral dos militares em ação toma uma dimensão mais importante do que o próprio aparato bélico empregado nas operações.

Transformações na política de segurança pública ocorreram, desde o final dos 1990, quando muitas organizações internacionais têm tentado disseminar não só no Brasil, mas em outros países da América Latina, o conceito de segurança "cidadã". A ideia por trás dessa iniciativa é a de, por um lado, romper com um modelo policial baseado na ideia de guerra contra o crime, mais especificamente guerra contra as drogas, que se tornou hegemônico no planeta até o final da guerra fria. A nova polícia não deveria mais legitimar o uso interno da força legítima pela guerra ou o combate ao inimigo, mas sim pela defesa dos direitos fundamentais dos cidadãos do país, o que amplia o campo das operações. Só quando se passa a dar mais importância à prevenção e ao respeito aos direitos da cidadania, o quadro de violência no país começa a mudar.

Os que apenas ressaltam a segurança no sentido estrito de combate ao crime ou, mais frequentemente, perseguição aos criminosos, estão sobretudo manipulando o medo da população e apostando nas reações primárias para ganhar os votos dela. Em outras palavras, ressaltar a segurança pública significa levar em consideração outras políticas públicas que compõem o quadro complexo e amplo da ordem pública sem a sensação de medo. Por isso mesmo é importante que esteja patente, a cada momento, a importância da manutenção de equipamentos coletivos da saúde, da educação, dos esportes, da iluminação pública, do esgotamento sanitário, assim como da ausência de prédios e veículos abandonados, barulho de tiros e a visão in loco de crimes sendo cometidos. Todas essas variáveis que interferem na sensação de segurança foram testadas nas várias pesquisas de vitimização, que foram realizadas na primeira década no século XXI, por terem impacto significativo sobre a sensação de segurança e o direito de ir e vir dos moradores das diferentes áreas da cidade (Zaluar et al., 2006). São elas que concretizam os direitos sociais das populações ditas vulneráveis que precisam dos serviços públicos para sair da vulnerabilidade.

Assim, defender o direito de ir e vir da população nas áreas mais marcadas por confrontos armados, manter o acesso aos equipamentos coletivos sempre desimpedidos, desarmar os que portam armas restritivas às Forças Armadas com as quais amedrontam as pessoas dali deveriam ser, no meu entender, as prioridades das operações policiais, nunca o combate ao tráfico ou ao uso de drogas. Essas prioridades constituem a forma mais eficaz de ganhar o apoio da população à presença também ameaçadora de caveirões, tanques e soldados ou policiais armados, alusivas da obediência inquestionável ao Estado e à autoridade (Zaluar, 2016).

Nada a ver com o que moradores dizem a respeito da revista de mochilas e bolsas em busca de armas e celulares, inclusive de grupos do WhatsApp que trocariam informações sobre operações e trocas de tiro. Assim aumentam o medo, a revolta, a desconfiança e a perda de um elemento importante nas guerras: a 
força moral dos combatentes perante a população que supostamente protegem.

Em segundo lugar, o medo dos que moram nas áreas conflagradas, dentro de favelas dominadas por traficantes ou milicianos e no entorno delas, é outra área pouco examinada para pensar uma política de segurança pública eficaz. Ela é crucial para entendermos a política que está na base da segurança pública, isto é, o apoio dado a um dos lados das batalhas violentas entre os comandos de traficantes, mas principalmente do conflito armado entre policiais e "bandidos". A disposição para a ação depende muito da força moral, pouco valorizada, vinda do julgamento feito pelos moradores sobre os protagonistas dessas guerras. Pois as guerras têm aspectos simbólicos para além da concretude muito dolorosa das armas cada vez mais letais. Para quem ali vive, não se trata de uma sensação disseminada de que algo pode vir a ocorrer em alguma rua da cidade, mas uma experiência real do barulho de tiros que invadem suas portas, janelas e paredes frágeis, da perda de parentes, vizinhos e amigos, da visão cotidiana das armas nas mãos e ombros de policiais e de traficantes ou milicianos (Zaluar et al., 2006). A vida por um fio. A vida por um tiro: não se sabe quem, onde e quando será disparado, mas se tem certeza de que o será. Os moradores reclamam não apenas da perda do direito de ir e vir, mas a perda da liberdade de melhorar a residência, pois pode desagradar alguém que tem conexões com os donos da boca, de conversar com os vizinhos, de fazer negócios imobiliários sem ter de pagar taxas, de melhorar de vida sem despertar a inveja ou a cobiça alheias (Zaluar; Conceição, 2007; Zaluar, 2016).

Como se dá o processo dos afetos que vão fazer parte da subjetividade desses moradores, de diversas idades, escolaridades, níveis de renda, gênero, religião, cor de pele? O que está sendo feito para ajudá-los a lidar com essas experiências traumatizantes que se repetem diariamente hoje em dia? Mais uma vez fica clara a conjunção entre a política pública de segurança e a de saúde pública, entre a segurança e a cidadania.

Não se pode negar, o que poderia resultar no agravamento da situação de medo e insegurança da população local, a grande capacidade de agressão violenta que hoje as facções criminosas têm, desde as favelas de cidades brasileiras. No Rio de Janeiro, as relações são profundamente assimétricas entre os traficantes e assaltantes armados e os demais moradores: estudantes, trabalhadores, donas de casa, crianças e idosos desarmados que, dependendo da ação, chamam os primeiros de covardes. Mas os que andam armados também sentem medo. Por isso tentam proteger-se dos grupos rivais de traficantes e dos policiais que os reprimem armando-se pesadamente. As barricadas que constroem dentro das favelas são feitas para bloquear a entrada de inimigos traficantes ou policiais entrarem em seus veículos, porém impedem igualmente o acesso à escola, ao posto de saúde, à cidade onde poderiam usufruir de equipamentos inexistentes no local de moradia. Barricadas são também a concretização dos entraves postos ao entendimento mútuo pelo uso da palavra e não da arma. Proteger escolas e 
demais equipamentos locais, assim como as entradas e saídas das favelas trará uma mensagem de paz facilmente compreensível e aceita pelos moradores das favelas dominadas por facções bem armadas.

Não se pode esquecer nunca de que paz, como ausência de guerra, significa ausência de assimetrias e dominação autoritária, seja do Estado, seja da facção criminosa. Fazer a paz nas favelas é desmantelar essa insuportável assimetria no território dominado, pois não é de bom alvitre substituir uma dominação autoritária por outra ainda mais refratária à lei maior e, portanto, a direitos do cidadão. "Paz, Justiça e Liberdade", lema do Comando Vermelho (CV) copiado pelo Primeiro Comando da Capital (PCC), termina na decisão dos chefes sobre a vida e a morte dos que venham a atrapalhar os negócios da quadrilha. $\mathrm{O}$ verdadeiro farol da ação dessas facções é "O crime fortalece o crime" e quem quer que bloqueie essa corrente será impiedosamente punido. Contudo, não há outra saída mais eficaz do que os projetos de pacificação que envolvam vários atores governamentais e não governamentais, mas mobilizem também os moradores das áreas mais diretamente afetadas.

Um ponto mais sensível nas operações de pacificação em curso em todo o país, especialmente no Rio de Janeiro, pois a legalidade delas depende de não haver restrições a direitos fundamentais assegurados pela Constituição, é a revista pessoal e, menos ainda, os mandados de busca e apreensão coletivos, esses já declarados inconstitucionais (Zaluar, 2016). Nessas ações todo o cuidado é pouco para não provocar a rejeição ou até mesmo a revolta da população. Mesmo que as denúncias de violação de direitos na abordagem policial (60\%) sejam mais de seis vezes superiores às violações perpetradas pelas forças do Exército (9\%), esse é o ponto nevrálgico para o consentimento da presença militar e, portanto, a cooperação necessária segundo os novos paradigmas do policiamento e combate ao crime. É isso que vai constituir as chamadas forças morais, importantes tanto na guerra quanto na paz, quando entendidas politicamente.

Passei muito tempo no início dos anos 1990 escrevendo sobre o medo dos moradores de favelas e os efeitos da violência sobre a vida cotidiana deles. Concluí que, além da discriminação sofrida por morarem no mesmo local que bandidos, o que poderíamos chamar violência simbólica, os favelados e moradores de bairros populares vivenciam de modo trágico a violência física: os repetidos tiroteios, as mortes cada vez mais frequentes de vizinhos, amigos, parentes, colegas, o temor de que seus filhos sejam atraídos pelas quadrilhas sem que compreendam muito bem o porquê e tornem-se mais um número nas estatísticas. A "guerra" pelo controle do ponto de venda, mas também por quaisquer motivos que ameacem o status ou o orgulho masculino dos jovens em busca de uma virilidade afirmada através da violência, ceifa vidas (Zaluar, 1994). As incursões policiais que voltaram a ser empregadas para caçar bandidos ceifam outras mais. Subjetivamente, a morte de seres humanos tornou-se banal, mas a aflição, o medo e a dor não. A vida cotidiana mudou muito, pois um número 
cada vez maior de moradores foi procurar proteção em igrejas neopentecostais, trazendo um novo conflito religioso que em alguns locais tornou-se agudo. Para enfrentar o medo, numa tentativa de fugir da violência e da sensação de insegurança e desconfiança, companheiras do medo, as famílias tenderam a se isolar cada vez mais dentro de suas casas e seus problemas individuais de sobrevivência ou de ascensão (Zaluar, 1994). Por fim, as associações de moradores perderam seu caráter de luta pela melhora das condições de vida dos moradores por que foram desvirtuadas nessa função de participação política quando passaram a ser controladas por milícias ou grupos de tráfico interessados em explorar os negócios informais ou ilegais na favela (Zaluar; Conceição, 2007).

O movimento de associações de moradores nos bairros pobres do Rio de Janeiro foi de fato profundamente afetado pela presença de traficantes de drogas e de milícias. Em meados da década de 1980, as principais associações de moradores tornaram-se alvo do interesse dos chefes do tráfico e das milícias, passando a maioria delas para o controle de seus prepostos. Nem aquelas em que o modelo participativo da democracia havia sido tentado, nem aquelas em que continuava a representação democrática, que implica um contato constante com políticos e um circuito de trocas entre eles e os moradores, foram poupadas (Zaluar, 1994). O velho tipo de político clientelista foi deslocado para dar lugar a um novo padrão mais violento imposto pelo grileiro de terra, pelo traficante de armas e de drogas, pelo empreendedor dos negócios tortuosos ou completamente ilegais, que passaram a controlar a entrada de políticos e de funcionários do Estado nas localidades (Zaluar; Conceição, 2007).

Em qualquer projeto de pacificação, a reflexão sobre a importância da vizinhança deveria estar presente. A paz precisa ser entendida como um modo de vida ou uma cultura, que se obtém, segundo John Dewey, na socialização do bom cidadão. Esse começa com o bom vizinho e o bom amigo, mas é também aquele que contribui para o bem-estar coletivo e não é mero carona ou eterna vítima dos outros. São as disposições ou atitudes mentais que dissolvem as chamas do ódio e da suspeita os ingredientes indispensáveis nessa construção do respeito, da responsabilidade, da cooperação e do diálogo. É isso que deve ser incentivado e construído nas interações entre os agentes governamentais, as forças policiais ou militares atuantes na pacificação e os moradores das áreas que se propõe pacificar, ou seja, eliminar os confrontos armados. As formas autoritárias de poder e a repressão injustificada, denominada covardia pelos cariocas mais humildes, ao contrário, trazem como resultado a conformidade forçada, o silêncio reprimido e a medo no diferencial da capacidade de defesa de cada segmento da população.

Temos de parar de repetir mecanicamente o mantra "o medo é mau conselheiro" para ressaltar que há outras formas de lidar com o medo, o qual definitivamente não pode ser evitado! Podemos evitar, sim, o ressentimento vingativo que olha para trás e eterniza o ódio e a violência, valorizando a vida ativa. Mui- 
tos líderes comunitários já trabalham nessa direção que é a de olhar para a frente e retomar a vida associativa local, fortalecer os projetos culturais e esportivos, a criatividade artística dos moradores. Nisso têm tido parceiros variados, como as ONG que apoiam essas iniciativas que já vinham sendo feitas por moradores voluntários desde os anos 1970; como as associações de moradores que ainda têm alguma autonomia, tentando recuperar a autonomia das associações de moradores perdidas para o crime organizado; como as escolas de samba e outros grupos artísticos antigos que sempre tiveram grande importância na construção da solidariedade entre vizinhos e entre moradores de bairros próximos, atingindo até mesmo camadas privilegiadas dos bairros mais prósperos da cidade.

Finalmente, o medo mais difícil de deixar de ser meramente reativo para se transformar em proativo é o medo difuso que afeta os moradores das cidades indiretamente envolvidos em situações de violência. Como não depende apenas das experiências vividas por eles, o medo fica mais marcado pelas ideologias, pelas mensagens transmitidas na mídia tradicional, hoje parcialmente controlada por igrejas neopentecostais, assim como nos novos meios de comunicação. Portanto, depende muito mais dos discursos feitos sobre a criminalidade violenta, as explicações ou as justificativas dela. Está na dimensão da política, embora parte considerável atue no sentido de eliminar a política com a escolha pela força repressiva, estatal ou não. A maioria das pessoas reage ao medo com providências sobre os seus caminhos e suas horas de exposição, por exemplo, evitando certos locais ou sair de casa à noite. Em alguns discursos, no entanto, o medo vem associado a outros sentimentos primários como o ódio ao outro, ao ressentimento e à vingança que eternizam a violência em circuitos intermináveis.

As explicações para o mal resultante da violência podem ser cósmicas ou terrenas, transcendentes ou não, dicotomizadas ou não. Como já escrevi anteriormente, quando são os outros os culpados pelo mal que nos atinge, quando as crenças são transcendentes e absolutas, a ideia do mal vem associada à demonologia e à classificação dos inimigos, dos rivais, dos estranhos e dos diferentes como agentes do demônio (Zaluar, 1994), base do fundamentalismo religioso. Nesses casos, os inimigos não passam de bodes expiatórios que devem ser sacrificados para que a ordem ameaçada pela sua presença possa vir a vigorar novamente. Essa concepção do mal, associada à maneira de resolver a violência através do sacrifício de alguém, é o que de mais primitivo as culturas humanas inventaram. Segundo René Girard, no plano religioso, ela teria sido superada pelo martírio de Cristo que sofreu e morreu por toda a humanidade, na tentativa de apaziguá-la; segundo Hobbes, no plano político, pela invenção do Estado e suas instituições de pena e castigo em nome de toda a sociedade, superando a vingança pessoal e de pequenos grupos. Nenhuma dessas alternativas à violência foi completamente exitosa, seja porque os ensinamentos de Cristo foram ignorados, criando culpados imaginários a eliminar, seja porque a justiça humana revelou-se falha, muito demorada e ineficiente, criando ilhas de impunidade para alguns. 
Assim, no plano do simbólico, existem concepções mais ambíguas ou mais absolutas do mal e do bem, de algum modo baseadas no deslizamento dos significados que vão adquirindo sinais negativos, criando a dicotomia bem $/ \mathrm{mal}$. A separação de coisas e pessoas que pertencem aos reinos absolutamente separados do mal e do bem é uma invenção de algumas religiões cristãs, especialmente claras em algumas igrejas neopentecostais que denunciam demônios identificados em pessoas e crenças humanas, numa reversão do processo histórico anterior. Essa concepção maniqueísta do mal teria desaparecido na Europa entre os séculos XVII e XVIII para dar lugar ao mal secular e desencantado, o que se explicaria, segundo Allan Macfarlane (1985), não pela predominância da ciência sobre a magia, mas pela confusão entre o bem e o mal que a economia mercantil disseminaria por conta de sua dependência do dinheiro. Citando Marx, e Simmel, ele conclui que, com o triunfo do capitalismo na Inglaterra, o mal absoluto estaria temporariamente desaparecido e o amor ao dinheiro seria também a fonte do bem, com a barganha (Macfarlane, 1985, p.72-3).

No Brasil, esse processo aparece invertido: justamente as religiões que celebram a prosperidade e o dinheiro promovem também o reencantamento do mal identificado com as religiões de matriz africana ou indígena (Zaluar, 1994). Diversas matrizes religiosas e culturais compõem um quadro extremamente complexo e ambíguo da definição de mal, algumas mais comuns em alguns setores da população, outras ainda mais repetidas nos meios de comunicação de massa, como na evangelização televisiva para rituais de descarrego do mal.

O medo do bandido tem nessa separação entre o bem e o mal uma matriz crucial. Deslizamentos simbólicos, baseados sobretudo na metonímia, na proximidade entre os signos usados, convergem numa direção socialmente clara onde estão os homens jovens e pobres, muitos de pele escura, mas não todos, que moram em áreas consideradas mais perigosas, onde acontecem conflitos armados entre membros de organizações ilegais, assim como operações policiais e militares. São eles que, metonimicamente próximos, vão sofrendo um processo claro de estigmatização pela escolha de um bode expiatório considerado como a raiz ou a fonte de todos os problemas da segurança pública: "bandido bom é bandido morto", ${ }^{3}$ leia-se "bandido bom da favela (ou da periferia) é bandido morto". O mal tem de ser completamente destruído, banido da sociedade. Não é por acaso que o autor dessa frase, além de ter sido militar, hoje aliou-se à direita religiosa evangélica que se destaca no debate parlamentar sobre as questões morais, tais como criminalização do aborto, anulação dos direitos LGBT, fim das pesquisas com células-tronco, entre outros. Ao contrário da direita católica, também conservadora, a direita evangélica tem defendido soluções mais repressivas para o aumento da criminalidade e se aliado a Estados, como Israel, que apostam na guerra. Para isso, foi necessário construir a imagem do bandido irrecuperável, ente do mal absoluto.

Em meados dos anos 1980, discursos registrados em pesquisas de opinião 
demonizavam o criminoso a tal ponto que não se referia mais a marginais ou maus elementos apenas identificados com a desordem ou o descontrole social, mas da encarnação de entidades diabólicas a ameaçar a ordem social abençoada por Deus (Zaluar, 1994). Infelizmente, continua valendo no século XXI, no qual o lugar dos prisioneiros e dos criminosos manteve-se crucial nessa nova maneira de pensar o mal, já não tão devedor da festa popular, nem da solidariedade, nem do associativismo popular como décadas atrás quando o discurso católico predominava entre os populares.

Agora o problema é que o Estado, que substituiu Deus nos interditos, deveria educar, treinar e dar emprego não conseguiu cumprir essa função nas últimas décadas e, no seu vazio, diversas crenças no diabo aparecem (Zaluar, 1994). O trabalhador é o bem; o bandido vadio é o mal, ressaltado pelo maniqueísmo das crenças religiosas fundamentalistas que se baseiam na Bíblia para justificar suas posições políticas. $\mathrm{O}$ trágico nessa cultura cindida entre o religioso e o jurídico instituído na responsabilidade individual é que a prisão rompe com esse sentido do trabalho e do humano em que a prisão acaba por instaurar um lugar do "paraíso", ou seja, um lugar em que não é preciso trabalhar para viver (Zaluar, 1994). Destarte, a prisão perde o sentido para os cidadãos temerosos de bandidos, o que resultou no notável aumento do apoio à pena de morte como saída para esse aparente absurdo.

Contudo, nas prisões brasileiras, os únicos privilégios são destinados aos que podem pagar por eles, ou seja, os chefes do crime organizado. Os outros são chamados de "caídos", não como os anjos que perderam o reino dos céus por quererem se igualar a Deus, mas porque não conseguem manter, à custa de recebimentos da organização criminosa na cadeia, as propinas necessárias para obter vantagens, inclusive a saída da prisão. Prende-se mal, julga-se mal, e estica-se pior ainda a permanência na prisão.

Eis a nossa maior área de atuação hoje, visto que é preciso continuamente desconstruir o discurso maniqueísta por uma outra narrativa que apresente modos de lidar com o medo mais eficazes no sentido de diminuir os níveis da criminalidade, violenta ou não, que alimenta perpetuamente o medo. A nossa aposta é melhorar ou tornar mais justo o sistema de justiça imperante no Brasil, ou seja, tornar funcional o Estado democrático de direito. Infelizmente continua sendo um trabalho interminável, uma tarefa de Sísifo, que é desmanchada todo dia pelo discurso imediatista, apressado e profundamente injusto de encontrar um culpado por tudo que provoca danos, sem verificar a inocência desse ser humano. Felizmente não é o único discurso nem mesmo o predominante na população que toma medidas práticas para evitar ser vítima de crimes.

Os que apenas ressaltam a segurança no sentido estrito de combate ao crime ou, mais frequentemente, perseguição aos criminosos estão sobretudo manipulando o medo da população e apostando nas reações primárias para ganhar votos, sem oferecer alternativas de paz. Em outras palavras, ressaltar o medo, 
estimular a população a se armar mais ainda para combater esse medo significa levar ao paroxismo a lógica da guerra.

Na lógica da prevenção, é importante que esteja patente, a cada momento, a importância da manutenção de equipamentos coletivos da saúde, da educação, dos esportes, da iluminação pública, do esgotamento sanitário, assim como da ausência de terrenos baldios e veículos abandonados, do barulho de tiros e da visão in loco de crimes sendo cometidos. Todas essas variáveis, que interferem na sensação de segurança, foram testadas nas várias pesquisas de vitimização realizadas na primeira década no século XXI, por terem impacto significativo sobre a sensação de segurança e o direito de ir e vir dos moradores das diferentes áreas da cidade. São elas que concretizam os direitos sociais das populações ditas vulneráveis que precisam dos serviços públicos para sair da vulnerabilidade. O direito de ir e vir, ameaçado pelo domínio armado nas favelas e adjacências, é o que garante que chegarão à escola, ao posto de saúde, ao hospital, às áreas de lazer da cidade. É o que garante também a entrada dos funcionários das empresas de água, luz e esgotamento sanitário, serviços básicos que estão sempre precisando de reparos e melhorias. Não há outro modo de restaurar a crença no regime democrático e a confiança entre os concidadãos, ou entre eles e os governantes. Se não virarmos o jogo, continuaremos presos nos mecanismos da inércia sistêmica e seus círculos viciosos de reprodução da violência como os aqui apresentados.

\section{Notas}

1 Este texto foi primeiramente apresentado na Reunião do Fórum Brasileiro de Segurança Pública em 2018.

2 Para os que sempre escutam tiros, $43,4 \%$ se sentem seguros ao sair de casa de dia, $33,8 \%$ pouco seguros, e $17,2 \%$, inseguros; enquanto $52,9 \%$ se sentem inseguros ao sair de casa à noite sozinhos, e 3,5\% se sentem muito seguros (Zaluar et al., 2006).

3 Em 2015, 60\% da população concordavam com isso; em 2018, segundo o Ibope, $50 \%$ homens mais do que mulheres.

\section{Referências}

BANFIELD, J. Crime and conflict, The new challenge for peacebuilding. International Alert Organization, 2014. Disponível em: <https://www.international-alert.org/ sites/default/files/CVI_CrimeConflict_EN_2014_0.pdf $>$.

BEAL, J.; GOODFELLOW, T.; RODGERS, D. Cities and conflict in fragile states in the developing world. Urban Studies Journal, v.50, n.15, p.3065-83, 2013.

BIESS, F. Feelings in the Aftermath. In: BIESS, F.; MOELLER, R. G. Histories of the Aftermath: The Legacies of the Second World War in Europe. Oxford; New York: Berghahn Books, 2010.

BOURKE, J. Fear, A Cultural History. London: Virago Press, 2006. 
HALL, G. S. Morale, The Supreme Standard of Life and Conduct. London: D. Appleton, 1920.

ELIAS, N. The Civilizing Process. Oxford: Blackwell Publishers, 2000.

MacFARLANE, A. The root of all evil. In: PARKIN, D. (Ed.) The Anthropology of Evil. Oxford: Basil Blackwell, 1985.

MEERLOO, J. A. M. Aftermath of Peace, Psychological Essays. New York: s. n., 1946.

OECD. Think global, act global: Confronting global factors that influence conflict and fragility. Paris: Organisation for Economic Cooperation and Development, 2012. Disponível em: <http://www.oecd.org/dac/incaf/globalfactors.htm>.

SAIN, M.; GAMES, N. Tendências e desafios do crime organizado na América Latina. In: NASSER, R.; MORAES, R. (Ed.) Brasil e a segurança no seu entorno estratégico: América do Sul e o Atlântico Sul. Brasília: IPEA, 2014. p.119-44.

SHKLAR, J. N. The Liberalism of Fear. In: HOFFMANN, S. (Ed.) Political Thought and Political Thinkers. Chicago: University of Chicago Press, 1998. p.3-20.

STEARNS, C. Z.; STEARNS, P. N. Anger. The Struggle for Emotional Control in America's History. Chicago: University of Chicago Press, 1986.

ZALUAR, A. Condomínio do diabo. Rio de Janeiro: Revan, 1994.

\section{4.}

. Integração perversa: pobreza e tráfico de drogas. Rio de Janeiro: Editora FGV,

Esculacho and other spoken meanings of pacification in Rio de Janeiro. Brasiliana, Journal for Brazilian Studies, v.4, n.2, 2016. Disponível em: <https://tidsskrift. $\mathrm{dk} / \mathrm{bras} /$ article/view/22170>.

ZALUAR, A.; CONCEIÇÃO, I. S. Favelas sob o controle das milícias no Rio de Janeiro: que paz? São Paulo em Perspectiva, São Paulo, v.21, n.2, p.89-101, 2007. Disponível em: <http://produtos.seade.gov.br/produtos/spp/v2ln02/v2ln02_08.pdf>.

ZALUAR, A.; PONCE DE LEON, A. C.; MONTEIRO, M. F. G.; LEÃO TEIXEIRA, M. L.; RIBEIRO, A. P.; MONTEIRO, R.; ROTH, A. L.; COSTA, L. Relatório Final da Pesquisa Domiciliar de Vitimização na Cidade do Rio de Janeiro 2005-2006. Rio de Janeiro: Nupevi/ IMS/ Uerj, 2006.

RESUMO - O artigo propõe retomar o debate sobre os medos, que não podem ser negados e continuam limitando a liberdade de ação dos indivíduos paralisados. Discute a doutrina liberal do que deve ser feito para impedir que a ação individual seja tolhida, especialmente no liberalismo do medo, doutrina política sobre a crueldade, imposição deliberada de dor física ou moral pelo mais forte sobre o fraco. Relativiza a visão do Estado como uma ameaça perene à liberdade dos cidadãos que devem se curvar à repressão, pois que há grupos organizados ou indivíduos fora do Estado, como na rede do Transnational Organized Crime (TOC), que intimidam ou matam pessoas em nome dos seus interesses individuais ou fins ideológicos coletivos. A saída mais usada é a de garantir que nenhum desses servidores do Estado possa intimidar alguém, a não ser pelo uso de procedimentos legais bem compreendidos e aceitos. A partir daí discute como a guerra às drogas afeta os combatentes servidores do Estado e cria reações e problemas 
psíquicos; os moradores das áreas urbanas mais violentas que, por causa dos traumas acumulados, fecham-se para a convivência e o associativismo; por fim, os moradores das cidades, mais afeitos à mídia e a ideologia fundamentalista religiosa.

PALAVRAS-CHAVE: Violência, Medo, Guerra às drogas, Crime organizado, Guerra irregular, Tráfico de armas, Maniqueísmo religioso, Segurança pública, Saúde pública, Estado democrático de direito.

ABSTRACT - The article aims to resume the debate on fears, which cannot be denied and continue to limit the freedom of action of paralyzed individuals. It discusses the liberal doctrine of what must be done to prevent individual action from being restrained, especially in the liberalism of fear, the political doctrine of cruelty, the deliberate imposition of physical or moral pain by the stronger on the weak. It relativizes the view of the State as a perennial threat to the freedom of citizens, who must bend to repression, since there are organized groups or individuals outside the State, such as the Transnational Organized Crime (TOC) network, who intimidate or kill people in the name of their individual interests or ideological ends. The most common way out of such a situation is to ensure that none of these State officials can intimidate anyone except by use of well-understood and accepted legal procedures. The article then discusses how the war on drugs affects civil servants and creates reactions and psychic problems; those living in the most violent urban areas who, because of accumulated traumas, shut themselves from social coexistence and associative life; and city dwellers, who become more media-oriented and susceptible to religious fundamentalist ideology.

KEYWORDS: Violence, Fear, War on drugs, Organized crime, Irregular war, Arms trafficking, Religious manicheism, Public security, Public health, Democratic rule of law.

Alba Zaluaré doutora em Antropologia pela Universidade de São Paulo (USP). Professora livre-docente de Antropologia na Universidade Estadual de Campinas (Unicamp). Professora titular de Antropologia da Universidade Federal do Rio de Janeiro. Leciona e faz pesquisa de 2012 até hoje no Instituto de Estudos Sociais e Políticos (IESP) / UERJ. @- azaluar1984@gmail.com / https://orcid.org/0000-0001-6892-3176

${ }^{\mathrm{I}}$ Universidade Estadual do Rio de Janeiro, Rio de Janeiro, Brasil.

Recebido em 28.3.2019 e aceito em 15.4.2019. 